\section{Decision-making in second-eye cataract surgery: can presence of Pulfrich phenomenon help?}

Department of Ophthalmology, Faculty of Medicine, Baskent University, Ankara, Turkey

\section{Correspondence:}

A Cetinkaya,

Baskent Universitesi

Hastanesi,

Goz Hastaliklari Anabilim Dali, Maresal Fevzi Cakmak Bulvari,

Bahcelievler 06490,

Ankara, Turkey

Tel: + 9031221503 49;

Fax: + 903122237333 .

E-mail: altugcetinkaya@

yahoo.com

Received: 29 March 2005 Accepted: 23 August 2005 Published online: 20 January 2006

The authors have no proprietary interest in any product mentioned in this article

Presented in part at the 29th Meeting of the European Strabismological

Association, June 2004, İzmir, Turkey

\begin{abstract}
Purpose To determine whether testing for the Pulfrich phenomenon (PP) can be used as a tool to assess the need for and optimal timing of second-eye cataract surgery.

Methods A total of 61 patients with $\log$ MAR 0 visual acuity (VA) after cataract surgery in one eye and logMAR 0.2-0.7 VA in the other eye were tested for PP using a computergenerated oscillating target at Baskent University Hospital. Only patients who had no ophthalmologic or systemic problem that could cause PP were included. In all, 15 normal patients with logMAR 0 VA in both eyes served as controls. The main outcome measures were presence and magnitude (measured by neutral density filters) of PP and presence of complaints related to binocular vision.

Results Of the 61 patients, $36(59 \%)$ and none of the controls were PP $(+)(P<0.001)$.

A total of $27(75 \%)$ of the PP $(+)$ patients had logMAR 0.7-0.4 VA, and nine (25\%) had logMAR 0.3-0.2 VA $(P=0.01)$. In all, 16 patients (all PP $(+)$ ) had developed binocular vision-related complaints since cataract surgery. The mean PP magnitude in these cases was significantly greater than the mean for the 20 patients without complaints $(1.2 \pm 0.5$ vs $0.6 \pm 0.4 \log$ units, respectively; $P<0.001)$. There was no significant difference between the mean VA in the complaint $(+)$ and complaint $(-)$ subgroups $(P=\mathbf{0 . 2 1 3})$. Conclusion PP testing may detect binocular visual dysfunction after first-eye cataract surgery; thus, it could help assess the need for second-eye cataract surgery on this basis.

Eye (2007) 21, 52-57. doi:10.1038/sj.eye.6702122; published online 20 January 2006
\end{abstract}

A Cetinkaya, S Oto and YA Akova

Keywords: binocular visual dysfunction; Pulfrich phenomenon; second-eye cataract surgery; uniocular pseudophakia

Introduction

Today, the world population includes a larger proportion of elderly people due to improved living conditions. Advanced technology and development of better products for ocular surgery have led to the situation where cataract surgery is now very common and the outcome is usually excellent. The success of cataract surgery is mainly assessed by testing monocular visual acuity (VA) after surgery. ${ }^{1}$ Most surgeons are unwilling to operate on both eyes in one session because of the potential risk of complications in both eyes at the same time. Usually one eye is operated initially, and once that eye regains good VA, the surgeon must decide whether or not to operate on the other one. He or she must weigh the costs and benefits of the second operation if the patient has reasonable binocular VA with a unilateral cataract.

If it is decided to proceed with the second-eye surgery, the next issue is the timing of the operation. There is still no consensus on optimal timing for this, and the decision is usually made based on the surgeon's own subjective criteria. In clinical practice, patients often complain that the cataractous eye interferes with vision in the operated eye, even when the cataractous eye has acceptable VA or contrast sensitivity. United States Government Guidelines suggest that the decision of when to extract a cataract should be based more on functional visual disabilities and less on clinical measures such as VA. ${ }^{2}$ However, as yet there is no universal gold-standard test 
that objectively and reliably predicts functional outcomes and quality-of-life outcomes in this patient group. This is a serious problem, because the strict policies of insurance companies and governmental health care organizations oblige the surgeon to delay the operation until there is significant loss of VA.

Some investigators have proposed that the Pulfrich phenomenon (PP), also known as the Pulfrich effect, might be one cause of visual disability in patients with unilateral cataract. ${ }^{3-5}$ The PP is a three-dimensional visual stereoillusion that was first identified by Carl Pulfrich in 1922: An object moving in front of the subject's eyes in the horizontal plane seems to follow an elliptical pathway when one eye is covered with a lightattenuating filter. ${ }^{6}$ This phenomenon is believed to be caused by a disturbance of the observer's perception due to a disparity between the latencies of the visual pathways of the two eyes. ${ }^{7,8}$ Previous reports have identified some common symptoms in a variety of conditions associated with PP, such as difficulty passing through doorways, difficulty judging traffic alignment when driving or crossing roads, and problems pouring tea, travelling in cars, playing card games, boarding trains, or placing objects centrally., ${ }^{4,6,9-12}$

Inspired by previous studies, we sought to determine whether PP testing could be used as a tool to assess the need for second-eye cataract surgery and possibly predict the best timing for such operations.

\section{Methods}

In total, 61 patients who were on the list for second-eye cataract operations at Baskent University Hospital were enrolled in the study. Informed consent was obtained from each patient and the study was in adherence to the tenets of Declaration of Helsinki. Each individual had $\log$ MAR 0 Snellen VA in the eye that had been operated. The technique for all the first-eye surgeries was phacoemulsification and posterior-chamber intraocular lens implantation, and none of the patients had developed intra- or postoperative complications. The VA range for the unoperated eyes was logMAR 0.7-0.2. The study also included an age-matched control group of 15 patients who had bilateral VA of $\log$ MAR 0 without glasses, and who had never undergone ocular surgery.

Each of the 61 cataractous patient eyes was tested for VA, pupillary light response, color vision, ocular motility, and intraocular pressure. VA testing was performed at $6 \mathrm{~m}$ using a standard Snellen chart, and best-corrected VA was recorded for each cataractous eye. The Snellen measurements were converted to logMAR format for statistical analysis. Slit-lamp biomicroscopy and funduscopy with a 90D lens were performed in each eye as well, and if the optic disc appeared at all suspicious on
Table 1 The interview questions that were asked before each patient was tested for Pulfrich phenomenon

Q1. Have you experienced any problems in your daily activities since cataract surgery? If yes, please specify.

Q2. Please mark if you have difficulty in any of the following vision-related activities:

- Passing through doors

- Placing objects on a surface

- Inserting keys in locks

- Pouring liquid into a cup

- Crossing roads

- Driving or car travel

- Walking past objects/people

funduscopy, visual field testing was carried out to check for disc abnormality. Patients were also questioned about systemic disease, current medications, and symptoms that might be related to optic nerve disease. None of the patients had ocular comorbidity that could cause PP.

Prior to testing for PP, each patient was briefly interviewed about difficulties related to motion stereopsis in their daily lives (Table 1). The questions were prepared in light of symptoms described in previous studies and according to our clinical experience. The first question asked about general problems that had arisen since cataract surgery. To avoid influencing the patient, no vision symptoms were specified. If the patient answered 'Yes' to Question 1, he or she was asked to select from a list of vision-related problems in the second question. The interview process was aimed at excluding complaints that were not related to binocular vision. A patient was considered complaint $(+)$ if she or he answered 'Yes' to Question 1 and selected one or more items from the list in Question 2. If the answer to Question 1 was 'No,' the patient was considered complaint (-). If the patient answered 'Yes' to Question 1 but the complaint she or he had was not listed in Question 2 or seemed unrelated to PP, then the patient was considered complaint (-).

Assessments for PP were carried out at least 6 weeks after surgery by an observer, who was masked to the results of the questionnaire. Immediately before this testing, each pseudophakic eye was carefully examined to ensure there were no cells/flare in the anterior chamber, no intraocular lens dislocation, no opacification of the posterior capsule, and no cystoid macular oedema or any lesion involving the optic disc or the papillomacular bundles. Testing for the Pulfrich effect was carried out using a computerized device (Ophthimus, Version 3.0, High Tech Vision, Göteborg, Sweden) that provided a consistent stimulus and a patterned background, properties that have been proven to increase the perception of PP. ${ }^{13}$ The target was a small 
$8 \times 8$-mm square that oscillated at $1 \mathrm{~Hz}$ in horizontal direction in the middle of the screen. A 15" NEC MultiSync XV15 colour monitor with a frame rate of $60 \mathrm{~Hz}$ screen was used. The target luminance was $20 \mathrm{~cd} / \mathrm{m}^{2}$ and the luminance of the background on which the target oscillated horizontally was $5 \mathrm{~cd} / \mathrm{m}^{2}$. The room luminance in front of the patient's eyes was $10 \mathrm{~cd} / \mathrm{m}^{2}$. All luminance levels were measured with a luminance meter (Hagner ED1, Sweden) before each test, and were adjusted if necessary.

Each patient was tested at $1 \mathrm{~m}$ from the screen with best-corrected distance glasses. The screen subtended an angle of $21^{\circ}$ at this testing distance, with the eye level corresponding to the level of the target on the screen. The person was asked to look at the moving target and try to identify whether it was moving in the horizontal plane or following an elliptical path travelling inwards and then away (or vice versa) from the screen. An individual was considered to be experiencing the Pulfrich effect if she or he perceived the target moving in an elliptical path. If an effect was noted, the patient was asked to determine the direction of movement to confirm that what he or she perceived was consistent with the Pulfrich effect. In each case where PP was detected, the condition was quantified by adding neutral density filters (NDFs) (Henry Louis Inc., Iowa, USA) in front of the operated eye in $0.3 \log$ unit increments from $0.3 \mathrm{log}$ units to $1.8 \mathrm{log}$ units. This was done until the perception of PP was abolished. Each of the filters was tested at least three times until a consistent response was obtained. The percentages of light transmitted by each of the NDFs used in the study are listed in Table 2 . The log unit value of the NDF that neutralized the elliptical motion was recorded as the magnitude of the Pulfrich effect. In each case where a patient did not report PP at first, the test was repeated with filters of varying strength (0.3-1.8 log units) placed in front of the cataractous eye. If the individual did perceive elliptical movement with a filter in place, she or he was asked if the movement path remained the same or was altered after the filter was removed. If there was still suspicion about the patient's recognition of $\mathrm{PP}$, the cataractous eye was covered and the patient was asked to describe the path of movement. The eye was then uncovered and the individual was asked if there was a change in the movement pattern. Patients who were uncooperative or showed inconsistent responses during repeated tests were not tested further and were excluded from the study.

Apart from the interview, the same testing was carried out in the control group. Each of these individuals was initially asked if she or he could perceive elliptical motion on the screen. If not, the PP effect was induced by placing a 0.3 or $0.6 \log$ unit filter in front of one eye and,
Table 2 The percentage of light transmitted by the neutral density filters used in the study

\begin{tabular}{lc}
\hline NDF (log units) & Light transmitted (\%) \\
\hline 0.3 & 41 \\
0.6 & 22 \\
0.9 & 12 \\
1.2 & 7 \\
1.5 & 5 \\
1.8 & 3 \\
\hline
\end{tabular}

NDF: neutral density filter.

Table 3 The demographic properties of the patient and control groups

\begin{tabular}{lcc}
\hline & $\begin{array}{c}\text { Patients } \\
(\mathrm{n}=61)\end{array}$ & $\begin{array}{c}\text { Controls } \\
(\mathrm{n}=15)\end{array}$ \\
\hline Mean age \pm SD (years) & $66.1 \pm 10.1$ & $65.5 \pm 6.4$ \\
Age range (years) & $42-84$ & $55-78$ \\
Sex distribution (M: F) & $21: 40$ & $5: 10$ \\
Mean VA (logMAR) & $0.40 \pm 0.15^{\mathrm{a}}$ & 0 \\
\hline
\end{tabular}

SD: standard deviation; M: male; F: female; VA: visual acuity.

${ }^{a} \mathrm{VA}$ in the cataractous eyes.

after the filter was removed, the patient was asked if there was a shift to horizontal motion.

Statistical analyses were performed using a commercially available statistical package (SPSS for Windows v. 9.0, SPSS Inc., Chicago, IL, USA). Two-tailed, independent sample $t$-tests were used to compare the frequencies of PP in the patient group and control group; mean VA in the PP $(+)$ and PP (-) patient subgroups; mean magnitude of PP with patients grouped according to VA level (logMAR 07-0.4 vs logMAR 0.3-0.2); and mean magnitude of PP in the complaint $(+)$ vs complaint (-) patient subgroups. $\chi^{2}$ testing was used to analyse the correlation between PP and VA.

\section{Results}

The demographic features of the patient and control groups are shown in Table 3. A total of 36 (59\%) of the 61 patients were identified as PP $(+)$ and none $(0 \%)$ of the control subjects was PP $(+)$. This difference in PP frequency was significant $(P<0.001)$.

The mean VA of the cataractous eyes in the $36 \mathrm{PP}(+)$ patients was significantly lower than the mean VA of the cataractous eyes of the $25 \mathrm{PP}(-)$ patients $(\log$ MAR $0.44 \pm 0.13$ vs $0.33 \pm 0.15$, respectively; $P=0.02$ ).

Of the 36 patients who were PP $(+), 27(75 \%)$ had VA in the range of logMAR $0.7-0.4$ and nine (25\%) had VA in the range of $\log$ MAR $0.3-0.2$. Presence of PP was significantly correlated with lower VA $(P=0.01)$.

The mean filter power required to neutralize the Pulfrich effect (ie, the magnitude of PP) was $0.9 \pm 0.6 \log$ 
units in the $36 \mathrm{PP}(+)$ patients overall, and was $0.9 \pm 0.6 \log$ units in the $\log$ MAR $0.7-0.4$ VA subgroup vs $0.6 \pm 0.5 \log$ units in the $\log$ MAR $0.3-0.2$ VA subgroup. Magnitude of PP was not correlated with VA level $(P=0.158)$.

Of the 61 patients, $16(26 \%)$ said they had experienced symptoms of binocular visual dysfunction since cataract surgery. All of these complaint $(+)$ individuals were PP $(+)$, and they represented $44.4 \%(16 / 36)$ of the PP $(+)$ group. The mean magnitude of PP in these 16 patients $(1.2 \pm 0.5 \log$ units) was significantly greater than the mean magnitude of PP in the $20 \mathrm{PP}(+)$ patients with no complaints $(0.6 \pm 0.4 \log$ units $)(P<0.001)$. The mean VA in this complaint $(+)$ subgroup (logMAR $0.44 \pm 1.3)$ was not significantly different from the mean VA in the complaint $(-)$ subgroup ( $\log$ MAR $0.38 \pm 0.16)$ $(P=0.213)$.

\section{Discussion}

Recent advances in cataract surgery, such as widespread use of phacoemulsification, safer, more rapid anesthetic techniques, and advanced intraocular lens technology, have made cataract surgery a more attractive operation for both patient and surgeon. However, if there is some degree of cataract formation in the second eye, soon after the first cataract surgery the patient will often complain that the unoperated eye interferes with the vision of the operated one. A number of previous reports have revealed that second-eye cataract surgery relieves such symptoms. 5,6,14,15 However, even if a patient complains, second-eye surgery may not be performed if he or she has acceptable VA and the surgeon feels it is unethical to operate in such cases.

A previous study investigated 208 otherwise healthy subjects who were waiting for second-eye cataract surgery. ${ }^{16}$ After the second operation was performed, binocular VA and contrast sensitivity were only slightly improved, but the patients reported fewer difficulties related to binocular vision and they had significantly higher stereoacuity. Elliott et $a l^{1}$ reported no significant improvement in binocular low-contrast VA in a group of patients who had undergone second-eye cataract surgery. However, they found significant improvements in some of the binocular measurements, such as high contrast visual acuity, face identity and face expression recognition, and word acuity. The authors have recommended second-eye cataract surgery to improve certain aspects of visual function, particularly for anisometropia. Harrad et al $^{17}$ and Pardhan and Elliot ${ }^{18}$ have suggested that binocular inhibition and binocular rivalry in patients with unilateral cataract could disturb normal monocular input from the eye with good sight, and that the resultant abnormal motion perception may contribute further visual disability.

In a paper published in 1925, Grimsdale ${ }^{19}$ proposed that the visual disturbances observed in patients with cataract might be due to PP. Diaper et al ${ }^{4}$ reported a case in which visual disturbance related to depth perception improved after second-eye cataract surgery. As well, this patient had perceived PP before the operation and the effect disappeared after the surgery. Scotcher $e t \mathrm{l}^{3}$ detected PP in 19 of 29 eyes with unilateral cataract and contralateral pseudophakia vs none in a young group of controls. In 12 of these 19 cases, the effect was abolished after second-eye cataract surgery. Based on this evidence that unilateral cataract can cause PP, the authors speculated that the Pulfrich effect might explain the visual disability evident in some cases of unilateral cataract where the disability cannot be attributed solely to poor VA, low contrast sensitivity, or poor stereoacuity.

In our study, more than half of the patients with unilateral cataracts (36 of 61 total) were PP $(+)$, whereas none of the age-matched control subjects perceived this effect. Thus, as reported by Scotcher et al, ${ }^{3}$ our findings confirm that unilateral cataract can cause PP. We found that presence of PP was correlated with level of VA in the cataractous eyes, but found no correlation between magnitude of PP and VA in this group. This may be because the retina adapts to the decreased illumination. The long course of cataract development may provide enough time for the retina to compensate for diminished brightness. Sadun et $a^{20}$ have stated that cataracts do not produce relative afferent pupillary defects for this same reason. Studies by Wolpert et $a l^{21}$ and Landrigan ${ }^{22}$ have shown that normal subjects with continuous use of uniocular filters can adapt to the Pulfrich effect in a relatively short period of time. However, there is a limit to the amount that can be compensated for by visual adaptation. Diaper et $a l^{4}$ suggested that this value was $0.2 \log$ units NDF (equivalent to $70 \%$ light transmission), by reporting a case of unilateral cataract with $1.49 \pm 0.07 \mathrm{~ms}$ of interocular conductance asymmetry and $0.29 \pm 0.1 \mathrm{log}$ units of interocular brightness difference. Differences greater than this value leaves a residual perceived interocular conductance delay that results in PP. However, these values are less than the values shown to be responsible for PP in optic neuritis patients. Heron et $\mathrm{al}^{23}$ declared a $44 \mathrm{~ms}$ of interocular asymmetry on delay campimetry in patients with retrobulbar optic neuritis. Rushton $^{12}$ evaluated an interocular latency difference of $2.4 \pm 1.8 \mathrm{~ms}$ in 41 normal subjects on Pulfrich pendulum, where the delay was outside these defined normal ranges in nine out of 18 multiple sclerosis patients with optic neuritis. A more recent investigation has measured the mean interocular asymmetry of conduction latency as $0.11 \pm 2.4 \mathrm{~ms}$ in 28 visually normal cases using an 
interocular temporal asynchrony system (95\% confidence limits were between -4.6 and $+4.8 \mathrm{~ms}){ }^{24}$ The value measured by Diaper et al in unilateral cataract was lower compared to these values declaring that unilateral cataract may cause a lesser delay in transmission than that of optic neuritis. Thus, this is probably the reason why PP is more common among patients with asymmetric nerve diseases rather than in patients with asymmetric cataract. In short, in case of optic neuritis, PP is the result of slower than normal conduction in the demyelinated nerve and these patients, lacking any mismatch illumination difference, do not adapt to the effect. However, PP is due to a retinal illumination difference in case of unilateral cataract, and these patients may show adaptation to this effect to a certain extent.

The presence of PP depends on many factors, including the speed of the moving object and its distance from the observer, but this effect is mainly related to decreased retinal illumination. ${ }^{25-27}$ Studies have shown that, compared with normal lenses, cataractous lenses transmit only a small fraction of light at all wavelengths. ${ }^{28-30}$ Zigman et $a l^{30}$ found that the typical light transmittance of an optically significant human cataract is less than $10 \%$ (equivalent to the effect of a $1 \log$ unit NDF). However, Ogle ${ }^{31}$ has shown that the magnitude of PP diminishes when very dense filters are applied to such eyes. Sadun and Libondi ${ }^{28}$ showed that only $2 \%$ of light (equivalent to the effect of a $1.8 \log$ units NDF) was transmitted through cataracts that caused 20/200 VA. These findings were our basis for excluding eyes with VA below logMAR 0.7 from the study.

We questioned our 61 patients about possible symptoms related to binocular vision, thinking that they might have experienced such difficulties due to onset of PP in the time since cataract removal. All 16 of those who had such complaints displayed PP, so presence of symptoms was correlated with presence of PP. However, presence of symptoms was not correlated with Snellen VA findings. In other words, the greater the magnitude of $\mathrm{PP}$, the more likely that the patient would complain about binocular visual disturbance irrespective of his or her Snellen VA level. These results strongly suggest that the patients' visual disturbances were due to PP, but not due to reduced VA.

Evaluation for the Pulfrich effect is a practical way to test for motion stereopsis. It may be helpful when investigating binocular vision complaints in patients who have undergone one cataract operation and have uniocular pseudophakia and some degree of cataract formation in the unoperated eye. In our study, complaints related to binocular vision were correlated with presence and magnitude of PP. Since PP testing reveals motion stereopsis, we believe that this type of assessment is a better determinant of real-life binocular seeing conditions than standard Snellen VA testing. Testing for PP may give patients, ophthalmologists, and insurance companies useful information about the need for (or urgent need for) second-eye surgery in relation to eliminating binocular visual disturbance.

\section{References}

1 Elliott DB, Patla A, Bullimore MA. Improvements in clinical and functional vision and perceived visual disability after first and second eye cataract surgery. Br J Ophthalmol 1997; 81: 889-895.

2 Cataract Management Guideline Panel, United States. Cataract in Adults: Management of Functional Impairment, Clinical Practice Guideline, Number 4. Agency for Health Care Policy and Research, Public Health Service, United States Department of Health and Human Services: Rockville, MD, 1993, AHCPR Publication 93-0542.

3 Scotcher SM, Laidlaw DA, Canning CR, Weal MJ, Harrad RA. Pulfrich's phenomenon in unilateral cataract. $\mathrm{Br} J$ Ophthalmol 1997; 81: 1050-1055.

4 Diaper CJ, Heron G, MacMillan ES. Correction of the Pulfrich phenomenon by surgery and laser. J Cataract Refract Surg 2002; 28: 369-372.

5 Lanthony P. Le phenomene de Pulfrich. J Fr Ophthalmol 1984; 7: 575-587.

6 Diaper CJ. Pulfrich revisited. Surv Ophthalmol 1997; 41: 493-499.

7 Julesz B, White B. Short-term memory and the Pulfrich phenomenon. Nature 1969; 222: 639-641.

8 Mansfield RJW, Daugman JD. Retinal mechanisms of visual latency. Vision Res 1978; 18: 1247-1260.

9 Heron G, Dutton GN. The Pulfrich phenomenon and its alleviation with a neutral density filter. Br J Ophthalmol 1989; 73: 1004-1008.

10 Friesen L, Hoyt WF, Birch AC, Weale RA. Diagnostic uses of the Pulfrich phenomenon. Lancet 1973; 2: 385-386.

11 Wertenbaker C, Gutman I. Unusual visual symptoms. Surv Ophthalmol 1985; 29: 297-299.

12 Rushton D. Use of the Pulfrich pendulum for detecting abnormal delay in the visual pathway in multiple sclerosis. Brain 1975; 98: 283-296.

13 Rogers BJ, Steinbach MJ, Ono H. Eye movements and the Pulfrich phenomenon. Vision Res 1974; 14: 181-185.

14 Laidlaw A, Harrad R. Can second eye cataract extraction be justified? Eye 1993; 7: 680-686.

15 Javitt JC, Steinberg EP, Sharkey P, Schein OD, Tielsch JM, Diener $\mathrm{M}$ et al. Cataract surgery on one eye or both. A billion dollar per year issue. Ophthalmology 1995; 102: 1583-1593.

16 Laidlaw DA, Harrad RA, Hopper CD, Whitaker A, Donovan JL, Brookes ST et al. Randomised trial of effectiveness of second eye cataract surgery. Lancet 1998; 352: 925-929.

17 Harrad RA, Whitaker A, Laidlaw DAH. Binocular rivalry in patients with unilateral cataract: a previously unidentified cause of visual disability. Invest Ophthalmol Vis Sci 1994; 35(ARVO suppl): 1964. 
18 Pardhan S, Elliott DB. Clinical measurements of binocular summation and inhibition in patients with cataract. Vis Sci 1991; 6: 355-359.

19 Grimsdale H. A note on the Pulfrich phenomenon with a suggestion on the possible clinical importance. $\mathrm{Br} \mathrm{J}$ Ophthalmol 1925; 9: 63-65.

20 Sadun AA, Bassi CJ, Lessell S. Why cataracts do not produce afferent pupillary defects. Am J Ophthalmol 1990; 110: 712-714.

21 Wolfpert DM, Miall RC, Cummings B, Boniface SJ. Retinal adaptation of visual processing time delays. Vision Res 1993; 33: 1421-1430.

22 Landrigan DT. Measurements of the Pulfrich effect over days of exposure. J Psychol 1984; 117: 125-133.

23 Heron JR, Regan D, Milner BA. Delay in visual perception in unilateral optic atrophy after retrobulbar neuritis. Brain 1974; 97: 69-78.

24 Carkeet A, Wildsoet CF, Wood JM. Inter-ocular temporal asynchrony (IOTA): psychophysical measurements of inter- ocular asymmetry of visual latency. Ophthal Physiol Opt 1997; 17: 255-262.

25 Nickalls RWD. The influence of target angular velocity on visual latency difference determined using the rotating Pulfrich effect. Vision Res 1996; 36: 2865-2872.

26 Lit A, Hyman A. The magnitude of the Pulfrich stereophenomenon as a function of distance of observation. Am J Optom Arch Am Acad Optom 1951; 28: 564-580.

27 Lit A. The magnitude of the Pulfrich phenomenon as a function of binocular differences of intensity at various levels of illumination. Am J Pyschol 1949; 62: 159-181.

28 Sadun AA, Libondi T. Transmission of light through cataracts. Am J Ophthalmol 1990; 110: 710-712.

29 Boettner EA, Wolter JR. Transmission of ocular media. Invest Ophthalmol 1962; 1: 776.

30 Zigman S, Groff J, Yulo T, Griess G. Light extinction and protein in lens. Exp Eye Res 1976; 23: 555-567.

31 Ogle KN. Disparity limits of steropsis. Arch Ophthalmol 1952; 48: 50-60. 